\title{
HEALTH RELATED QUALITY OF LIFE OF SURVIVORS OF TRAUMA SIX MONTHS AFTER DISCHARGE
}

\begin{abstract}
To investigate the health-related quality of life (HRQOL) of survivors of major trauma at six months following discharge, using two popular HRQOL tools.

A cross-sectional study was done on adult trauma survivors in Johannesburg. Subjects completed the EQ-5D and SF-36 HRQOL questionnaires. Additional demographic and clinical data were collected.

The majority of subjects reported some problems in usual activities and pain/ discomfort as measured with the EQ-5D at six months. The mean EQ-5D VAS was 68 ( \pm 26.1$)$. Lowest scores were reported in the role physical (44.6 \pm 41.6$)$ and role emotional (44.1 \pm 45.4$)$ domains of the SF-36. Mean SF-36 physical component summary (PCS) score (62.1 \pm 27.8$)$ was higher than mental component summary score (58.7 \pm 20.1$)$. EQ-5D VAS was found to be moderately correlated with age

\begin{tabular}{|c|c|}
\hline & $\begin{array}{c}\text { Schneiderman J. } \\
\text { (M Sc Physiotherapy) }^{1} \\
\text { Van Aswegen H. (PhD) }{ }^{1} \\
\text { Becker P. (PhD) }{ }^{2}\end{array}$ \\
\hline 2 & $\begin{array}{l}\text { Department of Physiotherapy, } \\
\text { University of the Witwatersrand, } \\
\text { Johannesburg. } \\
\text { Biostatistics Unit, Medical Research Council, } \\
\text { Pretoria. }\end{array}$ \\
\hline
\end{tabular}
$(r=-0.4 ; p=0.05)$. A negative correlation was found between SF-36 physical function score and ICU length of stay (LOS), hospital LOS and age $(r=-0.4(p=0.03),-0.4(p=0.03)$ and $-0.6(p=0.00)$ respectively). Statistical significance was observed in the correlation between age and SF-36 general health domain $(r=-0.4 ; p=0.02)$ as well as age and PCS score $(r=-0.5 ; p=0.01)$.

Trauma survivors in Johannesburg experience limitations in specific emotional and physical domains of HRQOL at six months after discharge. Age was associated with the level of self-rated health as well as limitations in general health and physical function. ICU and hospital LOS were associated with limitations in physical function. There is a need for physical and psychological rehabilitation after discharge from trauma intensive care.
\end{abstract}

KEY WORDS: HEALTH-RELATED QUALITY OF LIFE; EQ-5D; SF-36; TRAUMA; INTENSIVE CARE.

\section{INTRODUCTION}

Road traffic fatality rates in South Africa are almost double the global average and pedestrians are involved in more than half of these fatalities. In contrast to worldwide statistics, road traffic injuries rank second to interpersonal violence in South Africa (Norman et al, 2007). It is important to consider the non-fatal aspect of these statistics as for each death there are several survivors with permanent sequelae as a result of the injuries sustained. Patients with trauma who are

\section{Correspondence Author:}

Helena Van Aswegen

Department of Physiotherapy

Faculty of Health Sciences

University of Witwatersrand

7 York Road, Parktown

Johannesburg 2193

Email: Helena.vanaswegen@wits.ac.za treated in the intensive care unit (ICU) with mechanical ventilation (MV) suffer from muscle weakness and dysfunction due to the effects of critical illness and immobility on the human body (Topp et al, 2002).

Much research has been conducted on the health-related quality of life (HRQOL) of survivors of critical illness after ICU discharge in other parts of the world (Hofhuis et al 2009; Ulvik et al 2008; Cuthbertson et al 2005; Granja et al 2002). Many of these reports highlighted limitations in HRQOL related to physical functioning and emotional health in survivors of critical illness. There is, however, little known about the HRQOL of critical care survivors following ICU discharge in the South African population (Karachi, Hanekom and Faure 2011; Van Aswegen et al 2010). Van Aswegen et al (2010), reported poor HRQOL outcomes in 40 survivors of penetrating trunk trauma in Johannesburg at six months following discharge particularly in relation to physical functioning. Karachi et al (2011), reported poor HRQOL outcomes in 46 surgical ICU survivors in Western Cape at 12 months following discharge also in relation to physical functioning. Due to obvious differences between African and European demographics, there is a need to further investigate the HRQOL of survivors of major trauma in South Africa specifically in order to come to relevant conclusions about the quality of life of these survivors and as to whether results from South African studies are comparable to that of the international trauma population. Although many HRQOL tools have been used worldwide, the EuroQoL (EQ)-5D and Medical Outcomes Short Form-36 (SF-36) proved to be popular instruments in the assessment of HRQOL in 
ICU populations (Orwelius et al 2010). In order to allow for comparisons to be made between HRQOL of South African survivors of critical illness and trauma and that reported on an international level, it becomes important to use universally accepted HRQOL tools.

In the South African population, the EQ-5D has been used in measuring the HRQOL in non-ICU populations (Jelsma et al 2004; Jelsma et al 2005; Louwagie et al 2007); no evidence of its use in the assessment of HRQOL of the South African ICU population could be found. The SF-36 has been used to assess HRQOL in some non-ICU populations in South Africa (Benitha and Tikly 2007; O'Keefe and Wood 1996). Only two groups have used the SF-36 to assess HRQOL in critical care survivors in South Africa (Karachi, et al 2011; Van Aswegen et al 2011).

International reports confirm that survivors of critical illness experience delayed recovery of physical function at six months and even five years after discharge and emphasise the importance of rehabilitation interventions for such survivors to improve their HRQOL (Hough and Herridge 2012; Orwelius et al 2010; Ulvik et al 2008). Rehabilitation programmes exist in South Africa for people with chronic cardiac and/or pulmonary diseases, which have been shown to be effective in improving their ability to participate in cardiovascular exercises (improving ability to cope with work and activities of daily living [ADL]) and play a role in improving HRQOL. No rehabilitation programmes for survivors of critical illness in South Africa have been reported in the literature. Without knowledge of possible limitations in the HRQOL of survivors of major trauma, it is not known whether they too would benefit from a rehabilitation programme after discharge from the hospital. The aim of this study was to investigate the HRQOL of survivors of major trauma in Johannesburg six months after discharge using the EQ-5D and SF-36 (UK Version 1) HRQOL questionnaires. As the EQ-5D questionnaire had not been utilised in the South African ICU population as yet, the suitability of the questionnaire for this population required investigation.

\section{METHODS}

Permission was obtained from the University of the Witwatersrand Human Research Ethics Committee to conduct the study. Permission was obtained from the QualityMetric group to use the SF-36 questionnaire (UK Version 1) and from the EuroQoL group to use the EQ-5D questionnaire. The SF-36 questionnaire comprises 36 questions consisting of eight domains: physical functioning (PF), social functioning (SF), role limitation due to physical problems (RP), role limitation due to emotional problems (RE), mental health (MH), vitality (VT), bodily pain (BP) and general health perceptions (GH). The domains are summarised in summary scores namely physical component summary (PCS) score and mental component summary (MCS) score (Hofhuis et al 2009). The EQ-5D consists of two parts namely the EQ-visual analogue scale (VAS) (20 centimetre vertical scale) used to assess overall self-rated health (range 0-100) and a descriptive portion whereby the participant depicts health problems according to five items: mobility, self-care, usual activities, pain/ discomfort and anxiety/depression. The participant marks one of three levels of severity $(1=$ no problems, $2=$ moderate problems and $3=$ severe problems) for each of the five items and can then be classified into any one of 243 possible health states. Each state is referred to in terms of a five digit code (Hofhuis et al 2009; Badia et al 2001).

Permission from the management of two trauma centres in Johannesburg was obtained to conduct the study and to gain access to the hospital database and subject files. A retrospective cross-sectional study design was used for a cohort of adult subjects that survived trauma. In order to identify potential subjects for the study, the admission books and records of the respective ICUs were searched for those subjects who were discharged from ICU six months prior to the study. The subjects were contacted telephonically by the physiotherapist who was responsible for their care at the particular hospital and permission was sought from that person for the researcher to contact the subject regarding the study. The abovementioned physiotherapist also explained the aims of the study to the subject and excluded those not eligible. Male and female subjects, aged 18 years and older who suffered major trauma, received intubation and $\mathrm{MV}$ at one of the two trauma centres and were discharged six months ago, were eligible for inclusion. Subjects were excluded if they had an ICU length of stay (LOS) $<24$ hours, MV $<24$ hours, severe communication problems, diminished mental capacity, suffered lesions affecting the central nervous system, terminal malignancy, lived outside of Johannesburg and surrounding areas or were imprisoned after discharge. Recruitment of subjects began in May 2009 and extended to October 2010.

Once permission was obtained from the subject, the researcher contacted him/ her telephonically. The study aims and procedure was explained to the subject in more detail to make sure that he/she understood what was expected of them. An appointment was arranged between the researcher and the subject, at the particular trauma centre that the subject frequented, at a time that suited both. The researcher attempted to arrange appointments with subjects on the day of their scheduled follow up appointment with the trauma surgeon in order to reduce transport costs. Those subjects who could not be seen by the researcher on the day of their appointment with the surgeon were given a separate appointment date. They were reimbursed for their additional travel expenses. On the day of the scheduled appointment with the researcher, written informed consent was obtained. The subject completed the English (UK) SF-36 (version 1) and the English EQ-5D questionnaires in a selfadministered fashion. The researcher was present to assist the subject with any questions that were unclear to him/ her but in no way attempted to influence the subject's responses. Generally one participant at a time was seen by the researcher. The same researcher obtained written consent and was present while each participant completed the two HRQOL questionnaires.

Demographic information (age, gender, admission diagnosis, Glasgow Coma Scale, vital signs, full blood count and arterial blood gas results, ICU and hos- 
pital LOS) was collected using the subject's hospital file and ICU charts. The Acute Physiology and Chronic Health Evaluation (APACHE) II score for each subject was calculated from this information using a freely available online calculator as these scores were not readily documented on ICU charts or in medical files. The Injury Severity Score (ISS) was obtained from an administrator in the casualty department of the two trauma centres.

\section{Statistical Analysis}

SF-36 questionnaires were scored with the SF Health Outcomes ${ }^{\mathrm{TM}}$ Scoring Software package (Release 1.0) to convert raw scores into domain scores ranging from $0-100$ (transformed scores). There were no missing data. Values for PCS and MCS scores (norm-based scores) were obtained through merging of the domain scores. EQ-5D scores were calculated using the standard SPSS syntax developed by the EuroQol group. Frequency, percentage and cross tabulation were used to summarise categorical data pertaining to EQ-5D items, gender and trauma type. Continuous variables such as age, LOS, injury severity, EQ-5D VAS, SF-36 domain and summary scores were summarised using means and standard deviations (SD). Trauma type and gender categories were compared with respect to continuous variables using Student's T-test and one-way analysis of variance (ANOVA). In the latter, when necessary, pair-wise comparisons between three trauma groups were done using the Bonferroni approach. Where homogeneity of variance between groups could not be assumed, the oneway ANOVA for ranks was performed. EQ-5D items, trauma type and gender categories were compared using Fisher's exact test. The EQ-5D VAS, SF-36 scores were assessed in relation to age, hospital and ICU LOS using Pearson's- product-moment correlation coefficient. A p-value of $\leq 0.05$ was deemed statistically significant.

\section{RESULTS}

A total of 200 patients were admitted into the one trauma ICU in the six months prior to the study. Of these admissions, 31 deaths were recorded. The number of patients admitted into the second trauma ICU totalled 1115 and 65 deaths were recorded. The types of trauma seen at both centres varied between blunt and penetrating trauma and polytrauma. Not all admissions into the second trauma ICU presented with a diagnosis of trauma as this ICU also served as an overflow to the surgical and respiratory ICUs. Contact details were obtainable for 32 subjects at six months following ICU discharge. Of these, five subjects were excluded (not intubated and mechanically ventilated $(n=3)$; ventilated $<24$ hours $(n=1)$; para- plegia $(n=1))$; hence 27 subjects $(n=27)$ participated in the study.

Demographic characteristics are displayed in Table I. Missing data is owing to the lack of obtainable hospital records for some subjects. The vast majority of subjects were male $(81.5 \%)$. More than half of the subjects were involved in polytrauma $(51.8 \%)$ due to motor vehicle or pedestrian vehicle accidents. The average LOS in ICU and in hospital for this group of subjects was longer than 20 days.

Subjects took approximately five minutes to complete the EQ-5D questionnaire (range: 1-9 minutes). Extreme problems were reported in the pain/ discomfort $(\mathrm{n}=2)$ and anxiety/depression $(n=2)$ items of the questionnaire for a small minority of subjects at six months following ICU discharge (Table II). The majority of subjects had some problems in usual activities $(\mathrm{n}=18)$ and pain/discomfort $(\mathrm{n}=16)$ whilst a large number

Table I: Demographic characteristics of subjects at six months following discharge

\begin{tabular}{|c|c|c|c|}
\hline & Male $(n=22)$ & Female $(n=5)$ & Total $(n=27)$ \\
\hline $\begin{array}{l}\text { Age (years) } \\
\text { mean }( \pm S D)\end{array}$ & 37 (12.4) & 37.4 (13.4) & 37 (12.6) \\
\hline $\begin{array}{l}\text { APACHE II }(n=19) \\
\text { mean }( \pm S D)\end{array}$ & $11.8(9)$ & $16.8(14.1)$ & $12.7(10.3)$ \\
\hline $\begin{array}{l}\text { ISS }(n=20) \\
\text { mean }( \pm S D)\end{array}$ & $16.9(12.3)$ & $13.4(11.3)$ & $16.2(12.2)$ \\
\hline $\begin{array}{l}\text { ICU LOS (days) } \\
\text { mean }( \pm S D)\end{array}$ & $22.3(13.9)$ & $22.6(25.7)$ & $22.3(16.7)$ \\
\hline $\begin{array}{l}\text { Hospital LOS (days) } \\
\text { mean ( } \pm \text { SD) }\end{array}$ & $27(23.3)$ & 26.6 (24.4) & $26.8(10.3)$ \\
\hline $\begin{array}{l}\text { Type of trauma n (\%) } \\
\text { Blunt } \\
\text { Penetrating } \\
\text { Polytrauma }\end{array}$ & $\begin{array}{l}6(27.3) \\
5(22.7) \\
11(50)\end{array}$ & $\begin{array}{l}1(20) \\
1(20) \\
3(60)\end{array}$ & $\begin{array}{l}7(25.9) \\
6(22.2) \\
14(51.8)\end{array}$ \\
\hline
\end{tabular}

APACHE : Acute Physiology and Chronic Health Evaluation; ISS: Injury Severity Score; ICU: intensive care unit; LOS: length of stay

Table II: Descriptive item results of the EQ-5D six months after discharge expressed as number (percentage) $(n=27)$

\begin{tabular}{|l|l|l|l|l|l|}
\hline & Mobility & Self-care & Usual activities & Pain/discomfort & Anxiety/depression \\
\hline No problems & $13(48.1)$ & $17(63)$ & $9(33.3)$ & $9(33.3)$ & $12(44.4)$ \\
\hline Some problems & $14(51.9)$ & $10(37)$ & $18(66.6)$ & $16(59.3)$ & $13(48.2)$ \\
\hline Extreme problems & 0 & 0 & 0 & $2(7.4)$ & $2(7.4)$ \\
\hline
\end{tabular}


Table III: Comparison of EQ-5D items with trauma type and gender $(n=27)$

\begin{tabular}{|c|c|c|c|c|c|c|}
\hline \multirow[t]{2}{*}{ EQ-5D item } & \multicolumn{2}{|c|}{ Blunt Trauma } & \multicolumn{2}{|c|}{ Penetrating Trauma } & \multicolumn{2}{|c|}{ Polytrauma } \\
\hline & $\begin{array}{l}\text { Male } \\
(n=6)\end{array}$ & $\begin{array}{c}\text { Female } \\
(n=1)\end{array}$ & $\begin{array}{l}\text { Male } \\
(n=5)\end{array}$ & $\begin{array}{c}\text { Female } \\
(n=1)\end{array}$ & $\begin{array}{c}\text { Male } \\
(n=11)\end{array}$ & $\begin{array}{c}\text { Female } \\
(n=3)\end{array}$ \\
\hline \multicolumn{7}{|l|}{ Mobility } \\
\hline No problems & $2(33.3)$ & $1(100)$ & $4(80)$ & 0 & $5(45.5)$ & $1(33.3)$ \\
\hline Some problems & $4(66.7)$ & 0 & $1(20)$ & $1(100)$ & $6(54.5)$ & $2(66.7)$ \\
\hline Extreme problems & 0 & 0 & 0 & 0 & 0 & 0 \\
\hline \multicolumn{7}{|l|}{ Self-care } \\
\hline No problems & $2(33.3)$ & $1(100)$ & $4(80)$ & $1(100)$ & $6(54.5)$ & $3(100)$ \\
\hline Some problems & $4(66.7)$ & 0 & $1(20)$ & 0 & $5(45.5)$ & 0 \\
\hline Extreme problems & 0 & 0 & 0 & 0 & 0 & 0 \\
\hline \multicolumn{7}{|l|}{ Usual Activities } \\
\hline No problems & $1(16.7)$ & 0 & $2(40)$ & $1(100)$ & $4(36.4)$ & $1(33.3)$ \\
\hline Some problems & $5(83.3)$ & $1(100)$ & $3(60)$ & 0 & $7(63.6)$ & $2(66.7)$ \\
\hline Extreme problems & 0 & 0 & 0 & 0 & 0 & 0 \\
\hline \multicolumn{7}{|l|}{ Pain/Discomfort } \\
\hline No problems & 0 & $1(100)$ & $2(40)$ & 0 & $5(45.5)$ & $1(33.3)$ \\
\hline Some problems & $6(100)$ & 0 & $2(40)$ & $1(100)$ & $5(45.5)$ & $2(66.7)$ \\
\hline Extreme problems & 0 & 0 & $1(20)$ & 0 & $1(9.1)$ & 0 \\
\hline \multicolumn{7}{|l|}{ Anxiety/Depression } \\
\hline No problems & $1(16.7)$ & 0 & $2(40)$ & $1(100)$ & $7(63.6)$ & $1(33.3)$ \\
\hline Some problems & $4(66.7)$ & $1(100)$ & $3(60)$ & 0 & $3(27.3)$ & $2(66.7)$ \\
\hline Extreme problems & $1(16.7)$ & 0 & 0 & 0 & $1(9.1)$ & 0 \\
\hline \multicolumn{7}{|l|}{ VAS } \\
\hline Mean Score $( \pm S D)$ & $\begin{array}{c}55 \\
(28.9)\end{array}$ & 80 & $74.8(29.5)$ & 60 & $\begin{array}{c}77.1 \\
(21.9)\end{array}$ & $\begin{array}{c}49 \\
(10.2)\end{array}$ \\
\hline
\end{tabular}

*Results expressed as number (\%); VAS: visual analogue scale

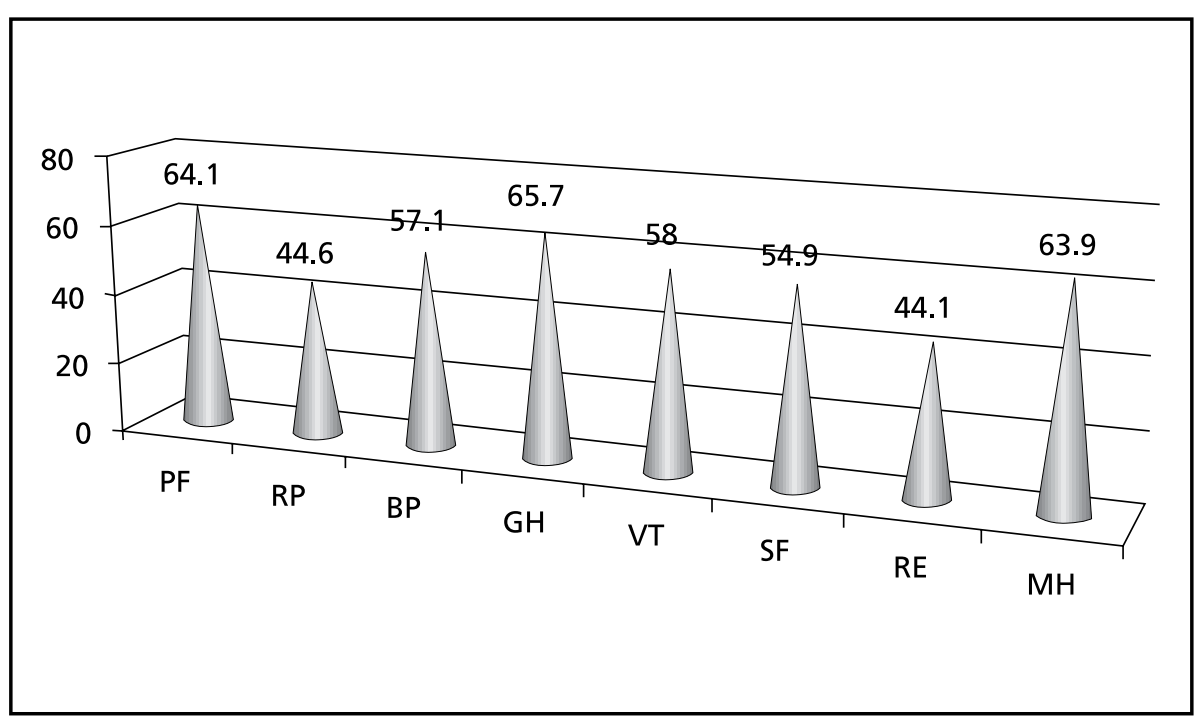

Figure I: Mean SF-36 domain scores at six months after discharge $(n=27)$ reported no problems in self care items $(n=17)$. A similar number of subjects reported no problems or some problems with mobility ( $n=13$ and $n=14$ respectively). A similar number of subjects reported no problems or some problems with anxiety/depression ( $\mathrm{n}=12$ and $\mathrm{n}=13$ respectively). The mean score for the EQ-5D VAS was $68( \pm 26.1)$.

Subjects took approximately 15 minutes to complete the SF-36 questionnaire (range: 5-25 minutes). A higher domain score indicates better HRQOL; a lower score indicates limitations in the respective domains of HRQOL (see Figure I) (Orwelius et al 2010). Highest 
Table IV: Comparison between EQ-5D items and the various outcome measures assessed.

\begin{tabular}{|c|c|c|c|c|c|}
\hline & ICU LOS & HOSPITAL LOS & APACHE II & ISS & AGE \\
\hline \multicolumn{6}{|l|}{ Mobility } \\
\hline No problems & $14.5( \pm 9.63)$ & $22.33( \pm 17.31)$ & $16.00( \pm 6.81)$ & $18.12( \pm 8.97)$ & $33.14( \pm 12.21)$ \\
\hline Some problems & $30.85( \pm 18.73)$ & $40.83( \pm 23.73)$ & $18.46( \pm 8.20)$ & $23.54( \pm 8,74)$ & $40.64( \pm 12.38)$ \\
\hline Extreme problems & _- & _- & - & _- & _- \\
\hline Statistical significance & $p<0.05$ & $\mathrm{p}<0.05$ & $p>0.05$ & $p>0.05$ & $p>0.05$ \\
\hline \multicolumn{6}{|l|}{ Self-care } \\
\hline No problems & $19.17( \pm 16.77)$ & $25.76( \pm 19.18)$ & $18.46( \pm 7.85)$ & $20.54( \pm 8.96)$ & $33.78( \pm 11.51)$ \\
\hline Some problems & $29.00( \pm 15.77)$ & $45.71( \pm 24.80)$ & $16.00( \pm 7.59)$ & $23.00( \pm 9.50)$ & $42.50( \pm 13.26)$ \\
\hline Extreme problems & - & - & - & - & - \\
\hline Statistical significance & $p>0.05$ & $\mathrm{p}<0.05$ & $p>0.05$ & $p>0.05$ & $p>0.05$ \\
\hline \multicolumn{6}{|l|}{ Usual Activities } \\
\hline No problems & $14.56( \pm 9.04)$ & $20.56( \pm 12.94)$ & $22.67( \pm 6.22)$ & $24.17( \pm 11.48)$ & $34.22( \pm 12.54)$ \\
\hline Some problems & $26.53( \pm 18.42)$ & $38.20( \pm 24.57)$ & $15.43( \pm 7.33)$ & $20.40( \pm 8.04)$ & $38.16( \pm 12.85)$ \\
\hline Extreme problems & - & - & - & - & - \\
\hline Statistical significance & $p>0.05$ & $p>0.05$ & $p<0.05$ & $p>0.05$ & $p>0.05$ \\
\hline \multicolumn{6}{|l|}{ Pain/discomfort } \\
\hline No problems & $14.56( \pm 11.26)$ & $21.89( \pm 15.96)$ & $18.80( \pm 5.93)$ & $19.80( \pm 11.56)$ & $30.22( \pm 8.15)$ \\
\hline Some problems & $25.18( \pm 18.46)$ & $36.36( \pm 24.69)$ & $16.92( \pm 8.45)$ & $20.29( \pm 7.56)$ & $39.53( \pm 13.79)$ \\
\hline Extreme problems & $38.00( \pm 1.41)$ & $52.00(-)$ & $19.00( \pm 9.90)$ & $34.00(0)$ & $44.50( \pm 10.60)$ \\
\hline Statistical significance & $p>0.05$ & $\mathrm{p}>0.05$ & $p>0.05$ & $p>0.05$ & $p>0.05$ \\
\hline \multicolumn{6}{|l|}{ Anxiety/Depression } \\
\hline No problems & $20.69( \pm 13.91)$ & $27.46( \pm 15.97)$ & $18.82( \pm 8.32)$ & $21.27( \pm 9.52)$ & $33.07( \pm 11.25)$ \\
\hline Some problems & $24.92( \pm 19.75)$ & $38.11( \pm 29.18)$ & $16.63( \pm 7.23)$ & $20.33( \pm 8.29)$ & $39.62( \pm 13.81)$ \\
\hline Extreme problems & $21.00( \pm 22.63)$ & $29.00( \pm 32.53)$ & $12.00(-)$ & $34.00(-)$ & $44.00( \pm 11.31)$ \\
\hline Statistical significance & $p>0.05$ & $p>0.05$ & $p>0.05$ & $p>0.05$ & $p>0.05$ \\
\hline
\end{tabular}

Results are reported as mean (standard deviation)

scores were reported in the GH domain (mean $65.7( \pm 27.7)$ ). Lowest scoreswere reported in the RP (mean $44.6( \pm 41.6)$ ) and RE (mean $44.1( \pm 45.4)$ ) domains indicating problems with work or other daily activities as a result of physical health and emotional problems respectively. Mean PCS score was $62.1( \pm 27.8)$ and mean MCS score was $58.7( \pm 20.1)$. Mean PCS was higher than mean MCS score.

A comparison of the EQ-5D items with the type of trauma and subject gender was done (Table III). More subjects with blunt or polytrauma reported having some problems in the mobility item compared to those with penetrating trauma who reported having no problems with mobility. The majority of subjects with blunt and polytrauma reported some problems in the usual activities item as well as in the pain/discomfort item. An equal number of subjects with penetrating trauma reported no problems and some problems with usual activities. A small number of the penetrating (20\%) and polytrauma (9.1\%) subjects described extreme problems in pain/ discomfort. A small number of subjects in the blunt trauma $(16.7 \%)$ and polytrauma $(9.1 \%)$ groups reported extreme problems with anxiety/depression. Males with blunt trauma had the lowest mean EQ-VAS score at six months compared to those with polytrauma who had the highest score. The EQ-VAS was found to be moderately correlated with age $(\mathrm{r}=-0.4 ; \mathrm{p}=0.05)$; thus with an increase in age, a decrease in VAS was evident.

Table IV illustrates comparisons between EQ-5D items and various outcome measures assessed. Regarding mobility, mean ICU LOS was 14.5 days $( \pm 9.6)$ and 30.9 days $( \pm 18.7)$ respec- tively for those reporting no problems and those reporting some problems on the EQ-5D questionnaire; therefore a longer ICU LOS resulted in more problems with mobility $(p=0.01)$. Those subjects who reported some problem in the mobility item of the EQ-5D were found to have had a prolonged period of hospital stay compared to those subjects who reported no problem with mobility $(\mathrm{p}=0.04)$. Subjects who reported having some problems in the self-care item of the EQ-5D had a longer hospital LOS compared with those who reported no problems $(\mathrm{p}=0.04)$.

The SF-36 PF score had a moderately negative association with ICU and hospital LOS and a strongly negative association with age (correlation coefficient $(\mathrm{r})=-0.4(\mathrm{p}=0.03),-0.4(\mathrm{p}=0.03)$ and $-0.6(\mathrm{p}=0.00)$ respectively); therefore, an increase in ICU and hospital 
LOS and an increase in age resulted in a decrease in the PF score. Statistical significance was observed in the moderately negative association between age and $\mathrm{GH}(\mathrm{r}=-0.4(\mathrm{p}=0.02))$ and age and PCS $(r=-0.5(p=0.01))$; hence, an increase in age was associated with a decrease in GH and PCS.

Subjects reported that the EQ-5D was more user-friendly and easier to understand than the SF-36. They found the English language used in the SF-36 questionnaire difficult to comprehend and required more assistance from the researcher in completing this questionnaire compared to the EQ-5D questionnaire; however the SF-36 provided a more detailed account of HRQOL. Due to the nature of data obtained from the SF-36 (continuous) and EQ-5D (categorical) questionnaires, a statistical comparison of results between the questionnaires could not be performed.

\section{DISCUSSION}

This study is one of a few that has investigated the HRQOL of survivors of major trauma in Johannesburg and South Africa. An important finding was that subjects presented with a reduction in specific emotional and physical domains of HRQOL at six months following ICU discharge.

Demographics related to gender and injury type in the current study are similar to that reported by other authors (Van Aswegen et al 2011; Ulvik et al 2008; Norman et al 2007). Subjects in this study had a prolonged ICU and hospital LOS which put them at risk for the development of physical debilitation. Bailey et al. (2007) stated that patients who received MV for a period longer than four days were at considerable risk of such debilitation. Prolonged MV has been defined by some as $>48$ hours and by others as $\geq 7$ days (De Jonghe et al 2007; Chang et al 2005). The duration of LOS reported in this study was substantially longer than that reported by some authors (Orwelius et al 2010; Ulvik et al 2008; Cuthbertson et al 2005). It should be noted that Cuthbertson et al. and Orwelius et al. reported on mixed populations of critical care survivors and not solely survivors of trauma. Our LOS results are not dissimilar to that reported by Van Aswegen et al (2011) who reported on survivors of penetrating trunk trauma only.

Subjects were found to experience problems in all five items of the EQ-5D at six months with some reporting extreme problems in the pain/discomfort and anxiety/depression items. The HRQOL reported in this study was reduced when compared to the subjects in the study by Granja et al. (2002) where HRQOL was measured using the EQ-5D six months after ICU discharge; however, Granja et al. (2002) studied a mixed ICU population where only four percent of the sample had a diagnosis of trauma. Since those that experience trauma are generally younger ( $<40$ years) and in good health prior to the incident, it might be reasonable to assume that their expectations of HRQOL after the traumatic incident will be reported as poor. This could explain why the results from the current study showed reduced HRQOL as measured with the EQ-5D. The EQ-VAS of the trauma population reported on by Granja et al. (2002) was 70 and in congruence with that reported in this study.

Reported HRQOL as measured with the SF-36 questionnaire showed that subjects in this study had not achieved optimal HRQOL in any of the domains nor with regard to the summary scores at six months. Lowest scores were found in the RP and RE domains. Subjects perceived having less physical limitation to HRQOL than limitations due to emotional factors in their daily lives at six months after ICU discharge. During informal discussions with the participants, it was found that less than half had returned to work. Arguably, the implication of this fact is that subjects struggled with a reduced sense of selfworth and lack of integration into their community. This fact could translate into the low reported MCS scores; however, a limitation of this study is that return to work was not assessed objectively.

With the exception of GH and VT, all SF-36 domain scores in the current study were decreased when compared with the domain scores reported by Orwelius et al. (2010). Their study sample was a mixed ICU population where $12 \%$ had a diagnosis of trauma. The current study did not investigate changes in HRQOL over time as did Orwelius et al. (2010). Orwelius et al. (2010) reported no considerable change in HRQOL over time (6-36 months after ICU discharge), and thus the measurement of HRQOL at six months (current study) provided a fair depiction of the subject's current state of HRQOL. Van Aswegen et al. (2011) measured HRQOL at one, three and six months after hospital discharge in survivors of penetrating trunk trauma. They reported low PCS scores at six months for subjects who had prolonged MV whereas MCS scores were comparable with that of a healthy group at six months. In the current study subjects reported higher mean PCS and MCS scores and also a higher PCS score than MCS score which is in contrast to that reported by Van Aswegen et al. (2011). These subjects however, suffered different types of trauma while the study by Van Aswegen et al. (2011) included only those with penetrating trunk trauma. The difference in type of trauma and the experience of such could bring about a difference in perception of HRQOL.

An association was found between age and EQ-VAS which is similar to the findings reported by Granja et al. (2002) who found age to be significant in the association with mobility, self-care, usual activities and pain/discomfort. Significance was reached in the association between ICU and hospital LOS and the mobility item of the EQ-5D in the current study and as well as between hospital LOS and the self care item; thus with an increase in time spent in ICU and in hospital, more limitation was found to be present in these items at six months following discharge. A moderate association was observed between ICU and hospital LOS and PF domain of the SF-36. Similarly, an increase in time spent in ICU and in hospital resulted in a decrease in the $\mathrm{PF}$ domain score. (Orwelius et al. (2010) described ICU LOS to have no association with HRQOL but hospital LOS was found to have a significant relationship with such.

It was reported that survivors of penetrating trunk trauma who were treated in ICU with MV, suffered from muscle weakness/dysfunction and limitations in exercise capacity up to six months following discharge due to the effects of 
critical illness and prolonged bed rest on the human body (Van Aswegen et al 2010). Exercise therapy has been shown to have beneficial effects on physical and psychological well-being and could potentially be a beneficial intervention strategy to improve HRQOL for survivors of major trauma after hospital discharge. Stathopoulou et al. (2006) conducted a meta-analysis investigating the effect of exercise intervention on mental health. It was hypothesized that the mechanism of action of the beneficial effects of exercise can be attributed to both psychological and physiological factors. Physiological factors included changes in metabolism and availability of central neurotransmitters. Psychological effects of exercise included changes in coping strategies and the interruption of negative thoughts. (Jones et al. (2003) investigated the effectiveness of a rehabilitation programme on the recovery of survivors of critical illness after discharge. They found that the SF-36 PF score for subjects in the rehabilitation group was closer to normal and significantly different from those in the control group. In light of the above it might be reasonable to suggest that exercise therapy, commenced after discharge from the hospital, might have a beneficial effect on the physical and psychological recovery of survivors of major trauma.

Some limitations to the current study include the fact that hospital records for a portion of subjects could not be attained. This was problematic as data for the whole sample could not be retrieved for APACHE II and ISS and may have influenced the significance of the associations of severity of illness with HRQOL. Subjects also found the English language used in the SF-36 questionnaire (Version 1) difficult to comprehend at times. Furthermore, as the questionnaire spoke of 'miles' and 'yards', some found it difficult to place the questions in context. It is recommended that HRQOL for trauma victims be assessed on ICU admission through proxies; even though there are known limitations to the use of proxies in HRQOL assessment, it may be possible to ascertain by how much HRQOL had deteriorated due to the traumatic insult as well as ICU and hospital LOS.
This study provides valuable baseline information on the HRQOL of survivors of various types of major trauma at six months after discharge and provides a platform for future research in this field in South Africa.

\section{CONCLUSION}

Survivors of major trauma experience limitations in emotional and physical HRQOL domains at six months after discharge. Age was associated with the level of self-rated health as well as limitations in general health and physical function. ICU and hospital LOS were associated with limitations in physical functioning. The results of this study support the recommendation that rehabilitation, in the form of physical and psychological interventions, be offered for survivors of trauma after hospital discharge to adequately address the identified limitations in HRQOL.

\section{REFERENCES}

Badia X, Diaz-Prieto A, Gorriz MT, Herdman M, Torrado H, Farrero E, Cavanilles JM 2001 Using the EuroQol-5D to measure changes in quality of life 12 months after discharge from an intensive care unit. Intensive Care Medicine 27:1901-1907.

Bailey P, Thomsen GE, Spuhler VJ, Blair R, Jewkes J, Bezdjian L, Veale K, Rodriquez L, Hopkins RO 2007 Early activity is feasible and safe in respiratory failure patients. Critical Care Medicine 35:139-145.

Benitha R, Tikly M 2007 Functional disability and health related quality of life in South Africans with rheumatoid arthritis and systemic lupus erythematosus. Clinical Rheumatology 26:24-29.

Chang AT, Boots RJ, Brown MG, Paratz J, Hodges PW 2005 Reduced respiratory muscle endurance following successful weaning from prolonged mechanical ventilation. Chest 128:553-559.

Cuthbertson BH, Scott J, Strachan M, Kilonzo M, Vale L 2005 Quality of life before and after intensive care. Anaesthesia 60:332-339.

De Jonghe B, Bastuji-Garin S, Durand MC, Malissen I, Rodrigues P, CerfC, Outin H, Sharshar T 2007 Respiratory weakness is associated with limb weakness and delayed weaning in critical illness Critical Care Medicine 35:2007-2015.

Granja C, Teixeira-Pinto A, Costa- Pereira A 2002 Quality of life after intensive care- evaluation with EQ-5D questionnaire. Intensive Care Medicine 28:898-907.

Hofhuis JGM, van Stel H, Schrijvers AJP Rommes JH, Bakker J, Spronk PE 2009 Conceptual issues specifically related to health-related quality of life in critically ill patients. Critical Care 13:118-120.
Hough CL, Herridge MS 2012 Long term outcome after acute lung injury. Current Opinion in Critical Care 18:8-15.

Jelsma J, Maclean E, Hughes J, Tinise X, Darder M 2005 An investigation into the health- related quality of life of individuals living with HIV who are receiving HAART. AIDS Care 17:579-588.

Jelsma J, Mkoka S, Amosun L, Nieuwveldt J 2004 The reliability and validity of the Xhosa version of the EQ-5D. Disability and Rehabilitation 26:103-108.

Jones C, Skirrow P, Griffiths RD, Humphris GH, Ingleby S, Eddleston J, Waldmann C, Gager M 2003 Rehabilitation after critical illness. Critical Care Medicine 31:2456-2461.

Karachi F, Hanekom S, Faure M. 2011 Healthrelated quality of life of patients 12 months following surgical intensive care discharge. The South African Journal of Physiotherapy 67(1): 28-34.

Louwagie GM, Bachmann MO, Meyer K, Booysen FR, Fairall LR, Heunis C 2007 Highly active antiretroviral treatment and health related quality of life in South African adults with human immunodeficiency virus infection: A cross-sectional analytical study. BMC Public Health 14: 244.

Norman R, Matzopoulos R, Groenewald P, Bradshaw D 2007 The high burden of injuries in South Africa. Bulletin World Health Organisation 85:695-702.

O'Keefe EA, Wood R 1996 The impact of human immunodeficiency virus (HIV) infection on quality of life in a multiracial South African population. Quality of Life Research 5:275-280.

Orwelius L, Nordlund A, Nordlund P, Simonsson E, Backman C, Samuelsson A, Sjoberg F 2010 Preexisting disease: the most important factor for health related quality of life long-term after critical illness: a prospective, longitudinal, multicentre trial. Critical Care 14:R67.

Stathopoulou G, Powers MB, Berry AC, Smits JA, Otto MW 2006 Exercise interventions for mental health: A quantitative and qualitative review. Clinical Psychology Science and Practice 13: 179-193.

Topp R, Ditmyer M, King K, Doherty K, Hornyak J 2002 The effect of bed rest and potential of prehabilitaion on patients in the Intensive Care Unit. AACN Clinical Issues 13:263-276.

Ulvik A, Kvale R, Wentzel-Larsen T, Flaatten H 2008 Quality of life 2-7 years after major trauma. Acta Anaesthesiologica Scandinavica 52:195-201.

Van Aswegen H, Eales C, Richards G, Goosen J, Becker P 2010 The effect of penetrating trunk trauma and mechanical ventilation on the recovery of adult survivors after hospital discharge. South African Journal of Critical Care 26:25-32.

Van Aswegen H, Myezwa H, Mudzi W, Becker P 2011 Health-related quality of life of survivors of penetrating trunk trauma in Johannesburg, South Africa. European Journal of Trauma and Emergency Surgery 37:419-426. 